\title{
ANALYSIS ON NON-UNIFORM FLOW IN STEAM GENERATOR DURING STEADY STATE NATURAL CIRCULATION COOLING
}

\author{
Susyadi $^{1}$ and T. Yonomoto ${ }^{2}$ \\ ${ }^{1}$ Center for Reactor Technology and Nuclear Safety - BATAN \\ Puspiptek, Tangerang 15310, Indonesia \\ ${ }^{2}$ Tokai-mura, Naka-Gun, Ibaraki., 319-1195 - JAEA
}

\begin{abstract}
ANALYSIS ON NON-UNIFORM FLOW IN STEAM GENERATOR DURING STEADY STATE NATURAL CIRCULATION COOLING. Investigation on non uniform flow behavior among U-tube in steam generator during natural circulation cooling has been conducted using RELAP5. The investigation is performed by modeling the steam generator into multi channel models, i.e. 9-tubes model. Two situations are implemented, high pressure and low pressure cases. Using partial model, the calculation simulates situation similar to the natural circulation test performed in LSTF. The imposed boundary conditions are flow rate, quality, pressure of the primary side, feed water temperature, steam generator liquid level, and pressure in the secondary side. Calculation result shows that simulation using model with nine tubes is capable to capture important non-uniform phenomena such as reverse flow, fill-and-dump, and stagnant vertical stratification. As a result of appropriate simulation of non uniform flow, the calculated steam generator outlet flow in the primary loop is stable as observed in the experiments. The results also clearly indicate the importance of simulation of non-uniform flow in predicting both the flow stability and heat transfer between the primary and secondary side. In addition, the history of transient plays important role on the selection of the flow distribution among tubes.
\end{abstract}

Keywords: Natural circulation, RELAP5, Non-uniform flow, Steam generator, Simulation

\section{INTRODUCTION}

As part of the joint research program in the field of nuclear safety between JAEA (formerly JAERI) and BATAN, investigation on natural circulation cooling has been conducted at JAEA. The investigation was in order to better understand the phenomena occurred in natural circulation cooling as this plays important role in long term heat transfer from the primary side of nuclear plant post LOCA accident. The focus of this research is the steam generator behavior in which non-uniform flow occurs among U-tubes during LOCA transient and long term natural circulation cooling. Tests conducted in LSTF found that there are several different modes of non-uniform behavior in steam generator. Those are single phase normal and reverse flows, two phase normal and reverse flow, cyclic fill and dump, stagnant vertical stratification, and reflux condensation [1,2]. YONOMOTO and ANODA [2] revealed that calculation for SBLOCA transient without taking into account non uniform behavior would over predict the heat transfer from primary side. Beside that, [2] also shows that low pressure long term 
cooling simulation of post LOCA accident calculation also provided very oscillatory result.

Several works have been performed in order to deal with non uniform behavior using different approaches. For high pressure case, SCHULTZ et al [3] used steam generator model consists of 3 different tubes. Although this approach could show the existence of some non uniform flow modes, it could not however, predict fill and dump phenomena occurred in the test. For low pressure case, analysis on stagnant flow using two parallel tubes with high flow resistance in one of the tubes as explained in [2] could reproduce the behavior better, though not sufficiently.

More specifically, this work is to look for a RELAP5 model that can be used to observe phenomena such as reverse flows, fill-and-dump, and stagnant vertical stratification as the reference [1] highlights these are the distinguishing characteristics between low and high pressure natural circulation cooling. In dealing with that, two general conditions were investigated i.e. at high pressure and low pressure. The investigation was simplified by looking at the phenomena in steam generator during steady state and only partial steam generator model was used. Boundary conditions matched with experimental data were applied to the model. In order to get the insight view on the flow non-uniformity, steam generator models having more than one tube were developed. Calculations were carried out for several conditions as conducted in test. This paper presents the modeling used in this work, boundary conditions and discussion on the calculation results for the 9-tubes model.

\section{EXPERIMENTAL FACILITY DESCRIPTION}

LSTF is a facility in JAEA that able to simulate PWR thermal hydraulic response for broad range of transient scenario, such as small break LOCA, steam generator tube rupture, natural circulation cooling, abnormal transient, etc. The facility mainly consists of an electrically heated core, two primary loops and a pressurizer. The design power of the core is $10 \mathrm{MW}$ with design pressure and temperature at $16 \mathrm{MPa}$ and $598 \mathrm{~K}$. Basically, this facility is a scale down of Westinghouse-type PWR reactor with scaling ratio of 1/48 for the volume and 1/1 for the height. Each of the two primary loops consists of a centrifugal pump and a steam generator. The steam generator has component characteristic similar to those in the referenced PWR. The similarities include the number of U-tubes, the height of steam generator, the position of feed water ring, etc. Some of the main characteristic of the steam generator is as shown in Table 1 . 
Table 1. Major Design Characteristic of LSTF steam generator.

\begin{tabular}{|l|c|}
\hline Max heat removal rate $(\mathrm{MW})$ & 35.7 \\
\hline Number of u-tubes & 141 \\
\hline Feed water flow rate $(\mathrm{kg} / \mathrm{s})$ & 2.76 \\
\hline Steam flow rate $(\mathrm{kg} / \mathrm{s})$ & 2.76 \\
\hline Average length of u-tube $(\mathrm{m})$ & 19.7 \\
\hline Pitch of u-tube $(\mathrm{mm})$ & 32.5 \\
\hline Pressure in SG Steam dome $(\mathrm{MPa})$ & 7.34 \\
\hline
\end{tabular}

As shown in the table, there are 141 U-tubes in the LSTF's steam generator. These tubes have 9 different groups and for each group there are different number of tubes. Details of these tubes geometry are shown in the following Table 2 .

Table 2. Details of U-tubes length.

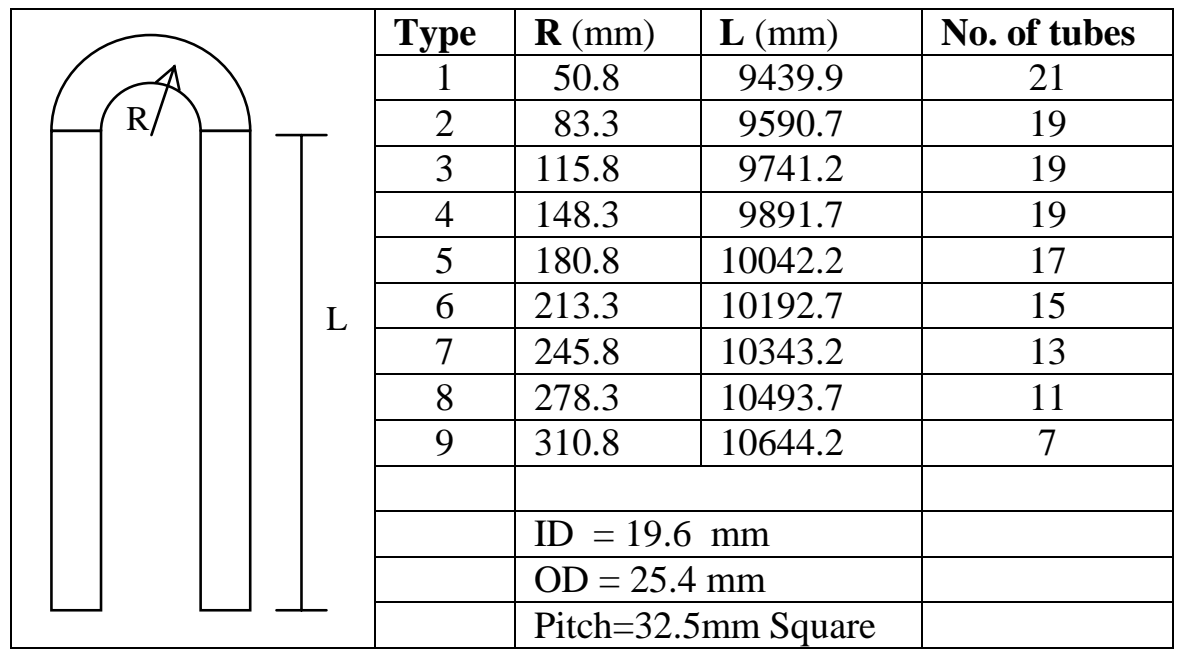

\section{EXPERIMENTAL DATA}

Data used in this work are steady state data observed during low and high pressure natural circulation tests: ST-NC-01 and ST-NC-17 that have been conducted in LSTF as explained in [1,2]. In general the experiments were conducted by draining primary loop mass inventory step wisely from the bottom of the core and then recorded the data after steady state condition were reached for each of the step. Each drain removed approximately $5 \%$ of the original mass inventory. In high pressure case, the experiment were conducted by keeping the secondary side pressure at about $6.7 \mathrm{MPa}$ and steam generator water level at about 9.5 meter. Meanwhile the primary side 
pressure was at nominal PWR working pressure which then decreased gradually as the mass inventory discharged. Similar practices were applied for the low pressure case. In this experiment however, the working pressure was about $0.13 \mathrm{MPa}$ for secondary side and about $0.3 \mathrm{MPa}$ for primary side. The core power were 1.4 MW and 0.94 MW for high pressure and low pressure tests respectively.

Qualitatively, results of the experiment showed that during high pressure natural circulation test, reverse flow was observed in the long U-tubes of steam generator during $100 \%$ of mass inventory, and fill-and-dump flow were observed in several U-tubes during $73 \%$ of mass inventory [1]. For low pressure natural circulation test, stagnant vertical stratification was monitored when mass inventory between 70 to $91 \%$ [2].

For the need of this work and based on qualitative result, two experimental data were chosen for each test. They are data at the $100 \%$ and $73 \%$ of mass inventory for for high pressure case and data at $100 \%$ and $75 \%$ of mass inventory for low pressure case.

\section{RELAP5 CODE DESCRIPTION}

RELAP5 is a transient analysis computer code developed originally at the Idaho National Engineering Laboratory (INEL) for the US Nuclear Regulatory Commission. RELAP5 is highly generic code that can be used for simulation of a wide variety of hydraulic and thermal transients in both nuclear and non-nuclear system involving steam, water, non-condensable and solute fluid mixture. The code contains system component model applicable to LWRs such as point neutronics model, pump, valve, separator, controls, etc. Improvements have been conducted to this code since its first development. Details of these improvements can be obtained in [5]. The RELAP5 version used in this analysis is RELAP5/Mod3.

\section{MODELING DESCRIPTION}

The model can be divided into two groups, primary side and secondary side. The primary side consists of two single-volume models that represent steam generator's inlet and outlet plenums and some parallel pipes that represent U-tubes. Hot liquid and vapor were supplied to inlet plenum using time dependent junction and will exit through outlet plenum to boundary condition.

The secondary side consists of more complicated structures. Annulus, pipe, separator, single volume and branch models are used to simulate the construction of secondary side. Pipe model is used as the place where water boils and vapor builds up. Feed water is supplied using time dependent junction to boiling pipe through annulus and will be converted into vapor. 
The time dependent junction is controlled by water collapsed level in the boiling pipe. From the boiling pipe, vapor will go through separator in which it will be filtered up from its water content. The water will be fed back to the boiling pipe while steam will exit through steam line pipe.

In order to get detail view of the phenomena in steam generator, the U-tubes and boiling pipe of the model are divided into several small calculation volumes. The boiling pipe model is divided into 18 volumes while the U-tube models are divided into volume cells between of 32 to 36 depending on their length. Nodding of the model is shown in the following Figure 1.

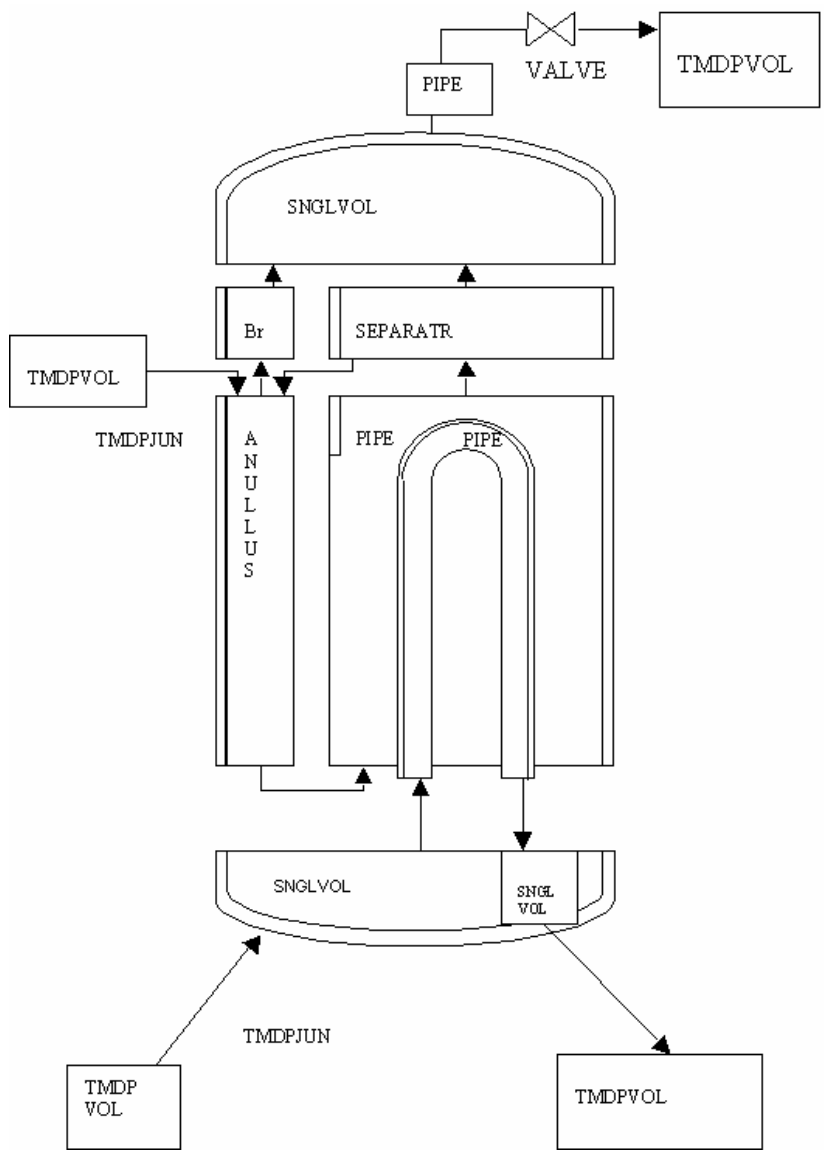

Figure 1. Nodal of Steam Generator model.

In order to facilitate the need of this research which is to observe the main non-uniform flow modes in steam generator, two models were developed. They are steam generator models using single-tube and 9-tubes. 
The steam generator with single-tube model is basically adopted from the LSTF's system-wide input deck model that previously has been used for other calculation. In this model, all U-tube is represented by single tube that will be the place of heat transfer from primary side to secondary side. The 9-tube model is an extension of the single tube model. The 9-tube model were selected as physically the steam generator has 9 different tube length (see facility description section). Based on the modeling above, RELAP5 input decks were then created.

\section{Boundary Conditions}

As stated before, investigation on natural circulation cooling was focused on the behavior inside steam generator. For this reason the model prepared was partial only, and boundary conditions were applied as needed. In primary side, the temperature and mass flow of both liquid and vapor were imposed at the inlet boundary. The working pressure of the primary side was set using outlet boundary. This boundary for some calculation was adjusted to make the differential pressure between inlet and outlet plenum matches with experimental data. For the secondary side, the boundary conditions imposed were feed water temperature, steam generator water level, and saturated temperature/pressure of steam in the steam line. The feed water flow was arranged so it depended on the water level in the boiling pipe. If the level exceeded the-prescribed limit, feed water would stop and if the water level dropped below the prescribed limit, feed water would flow.

\section{RESULTS AND DISCUSSIONS}

Using boundary condition explained before, several simulation were executed. Different number of tube models were used. Single tube model was executed as the base for comparison but will not be explained further because this model can not deal with non uniform flow. The 9-tubes models was executed to get the detail insight on what happens in U-tubes.

\section{Nine-tubes Model, High Pressure Case}

In steady state calculation for $100 \%$ of mass inventory case, the result shows that at least there are three flow circumstances in U-tubes depending on how the boundary conditions are approached, i.e. forward flow in all tubes, reverse flow in short tubes while forward in other tubes and reverse flow in long tubes while forward in other tubes.

For all cases, the steady differential pressure is positive, meaning that pressure in outlet plenum is higher than in inlet plenum. The positive differential pressure can be understood by comprehending that as the flow runs slowly and the secondary side water temperature distribution is almost uniform (less than $1 \mathrm{~K}$ different between upper and lower levels), the heat is 
mostly transferred in the upside of tube. In other word the cooling of primary fluid temperature mostly occurs in the upside of u-tube. That condition makes average temperature in upside is higher than in downside so overall water density in the upside tubes are lower than overall density in the downside. The density in downside is higher than in upside tube, this means the pressure in outlet plenum is higher than in inlet plenum.

The first flow circumstance, which shows disagreement with qualitative result stating non-uniform flow among U-tubes, was obtained by putting all boundary condition similar to the test data while initial condition for each component was set with uniform arbitrary values. This situation shows that not only the present boundary condition is behind the cause of the reversing flow. A trial run by reducing the flow rate to a certain lower value and then returning back the flow to the original value ends up with the second stable circumstance, in which flows in short tubes were reversed.

The second flow circumstance shows that the preferred reverse flow during unstable flow was in short tube. This result differs from the qualitative test result which indicated that the preferred tube to have reverse flow was the long tube. This different occurred because realistic transient in the test was not reproduced in this steady state calculation. However, from the previous explanation it can be understood that if during the slowing down of the flow, the differential pressure was negative, it is possible to have the long tube flow reverses. The differential pressure could go to negative value if the average temperature of the upside is lower than the down side. It can happen if inlet temperature drops for some time. As previously recognized, the flow rate as much as $5.8 \mathrm{~kg} / \mathrm{s}$ is low enough in which a partial water needs for about 110 seconds to move from the inlet to the top of U-tube. If lower temperature water enters for this period of time, it is possible to get the differential pressure negative. An execution using this approach ends up with result in the third stable circumstance where flows in two long-tubes are reversed.

When reverse flow occurs, colder water from outlet plenum will enter to inlet plenum. This condition will decrease the inlet plenum temperature to some degrees. Calculation using 9-tubes model in which three tubes having reverse flow exhibits that the temperature decreases for about $3.3 \mathrm{~K}$. The three long-tubes having reverse flow in this model are equivalent with $22 \%$ of tubes in real steam generator. Although some of tubes have reverse flow, however, comparison shows that the amount of heat transferred from primary side is almost no difference between the calculation with all tubes having uniform forward flow and the calculation with some tubes having reverse flow. The discrepancy was less than $0.3 \%$.

These three flow circumstances show that transient before final steady state play important role on selection of the flow modes among U-tubes. Combination of flow and temperature transient will determine whether a reverse flow on short or long tube will be obtained or not. This result 
complies with statement in [1] that the behavior of tubes is somehow depending on the history of the transient through which the final condition is reached.

In calculation using $75 \%$ of mass inventory case data, the fill-and-dump phenomena can be observed in model with 9 tubes. Fill-and-dump is intermittent flow occurred in tubes having enough supply of vapor so that condensation occurred in the upper side of tubes. When the accumulated water produced from condensation reaches the top of U-tube, it will then be discharged quickly to the down side tube [1]. This periodic fill-and-dump can be seen in Figure 2, in which the mass flow rate on the top of tube becomes periodically fast in short period. The $75 \%$ of mass inventory calculation result shows that the fill-and-dump occurred in $68 \%$ of total tubes while in the other tubes, continuous oscillatory flows exist. Calculation also shows that the fill-and-dump period among the tube comes out of phase and the differential pressure is about close to zero. The existence of fill-and-dump make the outlet flow rate becomes slightly oscillatory. This situation excellently matches with the qualitative result explained in [1].

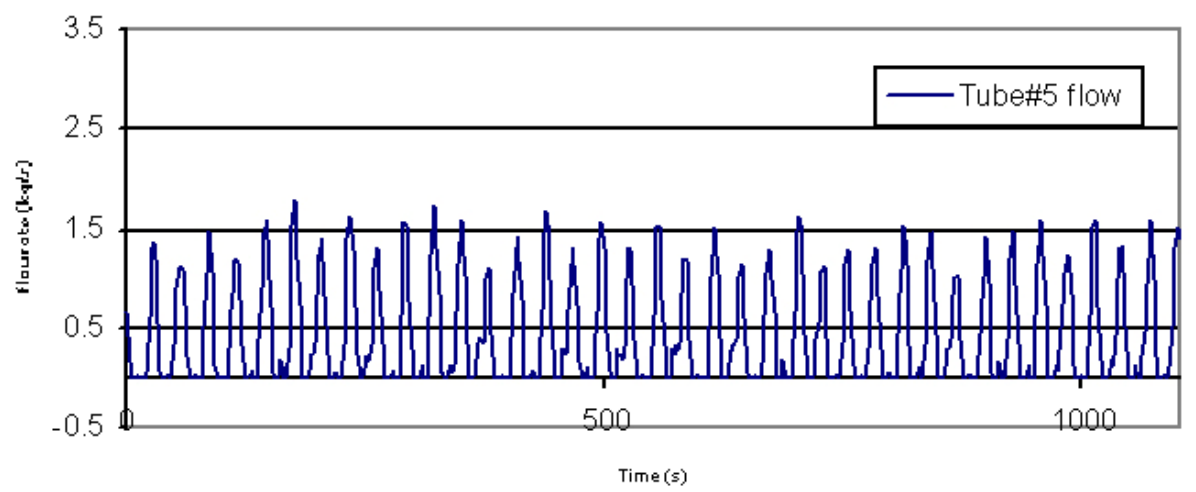

Figure 2. Fill-and-dump phenomena in tube\#5.

In term of heat transfer from the primary to secondary side, calculation indicates that the existence of fill-and-dump in some tubes affects the heat transfer rate. Although the result shows a little oscillatory, comparison on average value reveals that calculation using 9-tubes model transfers $6 \%$ less heat than the single tube model does for $73 \%$ of mass inventory. It can be expected that if more tubes have fill-and-dump mode (e.g. for lower mass inventory), the discrepancy will be greater. This discrepancy shows the important of non uniform consideration in dealing with steam generator during LOCA calculation. Failing to use model that able to capture fill-and-dump phenomena would end up with faster reduction of primary side pressure. 


\section{Nine tubes model, Low Pressure Case}

Like in the high pressure natural circulation cooling calculation, different steam generator model were also used for low pressure calculation. When calculation was performed using the 9-tubes model for $100 \%$ of mass inventory, a stable flow circumstance was achieved when some tubes have reverse flow (see Figure 3). With the existence of reverse flow, vapor supply was somehow balanced with condensation rate in U-tube so oscillatory was not occurred. However, in conducting the calculation some difficulties was encountered in order to reach stable result. Unstable oscillatory flow would occur if arbitrary initial conditions were used for the intended boundary condition and once the instability occurs, the condition inside steam generator would never gets stable. Example of the unstable oscillatory flow can be seen in Figure 4. This situation is typically occurred in low pressure natural circulation calculation only and somehow makes calculation fail to converge on a stable value.
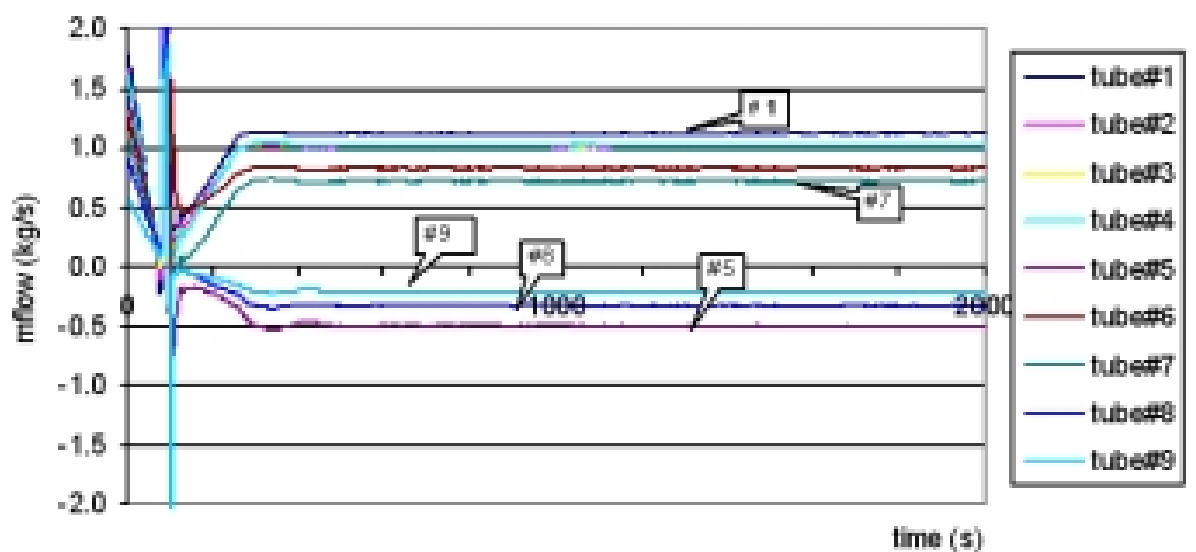

Figure 3. Stable U-tube flow, 9-tubes model case.

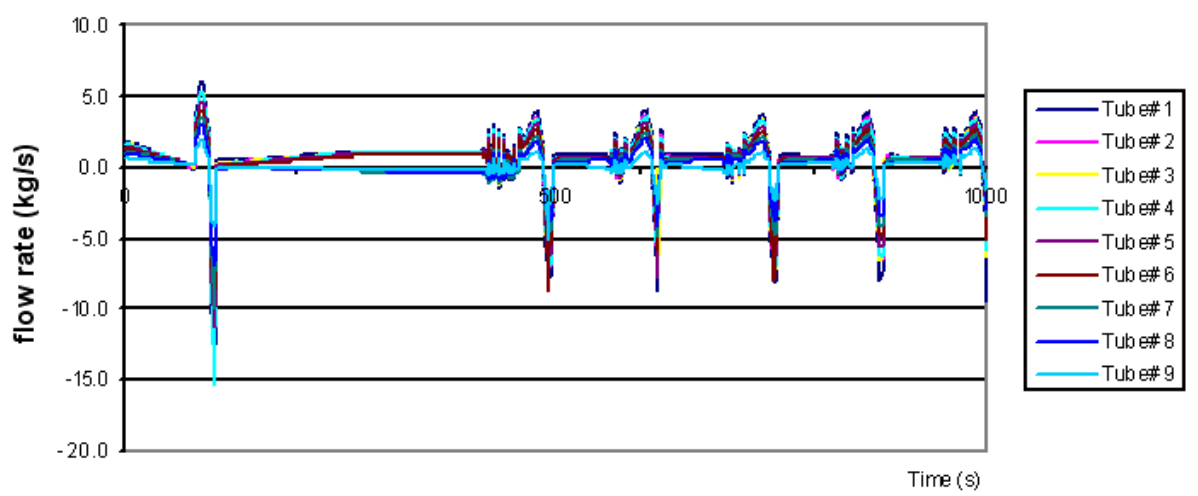

Figure 4. Oscilatory flow in U-tubes, 9-tubes model case. 
Realizing the problem, an approach before implementing the steady state boundary condition was performed. The approach used was by applying the primary side with sufficiently high pressure and high flow rate. Using this method, stable circumstance at high flow rate could be achieved. The flow was in forward direction for all tubes. When such circumstance reached steady, calculation was continued by making a transient simulation to the boundary condition matched with experimental data. The boundary pressure was reduced quickly enough into experimental data value while at the same time the flow was reduced into very low rate. After that, slowly the flow rate was increased to the intended boundary value. Using this approach, it was expected that flow in U-tubes would reconfigure itself and went to directions based on the condition at that time.

Similar problem encountered in $100 \%$ of mass inventory case was also happened for $75 \%$ of mass inventory calculation. The unstable oscillatory flow result would occur when arbitrary initial condition applied. In the $75 \%$ of mass inventory calculation, the stable result of the 9-tubes model provides qualitative outcomes as the one observed in the test. Stagnant flow in most of tubes and continuos two phase flow in some other tubes were presented. The result shows that the tube \#1 and \#2 have continuos flow while in tube \#3 until tube \#9 the flow were stagnant (see Figure 5). YONOMOTO and ANODA [2] explained that the stagnant flow exists because of the temperature distribution at secondary side which has contour in which the bottom and topmost parts have lower temperature than in the middle. This temperature profile exists due to the saturated pressure in secondary side at low pressure is comparable with the static head pressure of the water level. When feed water enters to the bottom of boiling pipe, its temperature will increase to saturated value as it flows up. The saturated temperature is affected by the local pressure which decreases as its position increases. So when the temperature goes up and reaches saturated value at about in the middle position, it will then decrease to lower value because the pressure is lower. The secondary side temperature profile like this would make the condensation and evaporation occurred in primary side along the U-tube. Inside the U-tube, the vapor will be produced in the middle of tube after condensation in the lower side. As the vapor moves up following the evaporation, the condensation will occur again in the upper part of U-tube. This phenomenon happens for both the upside and downside of the U-tube. When condensation and evaporation reach balanced after the transient that leads to vapor existence in the tube, this profile will bring stagnant flow in the tube. The primary flow then will be directed to other tubes which do not have vapor slug. Using partial model YONOMOTO and ANODA showed this evaporation and condensation balance. 


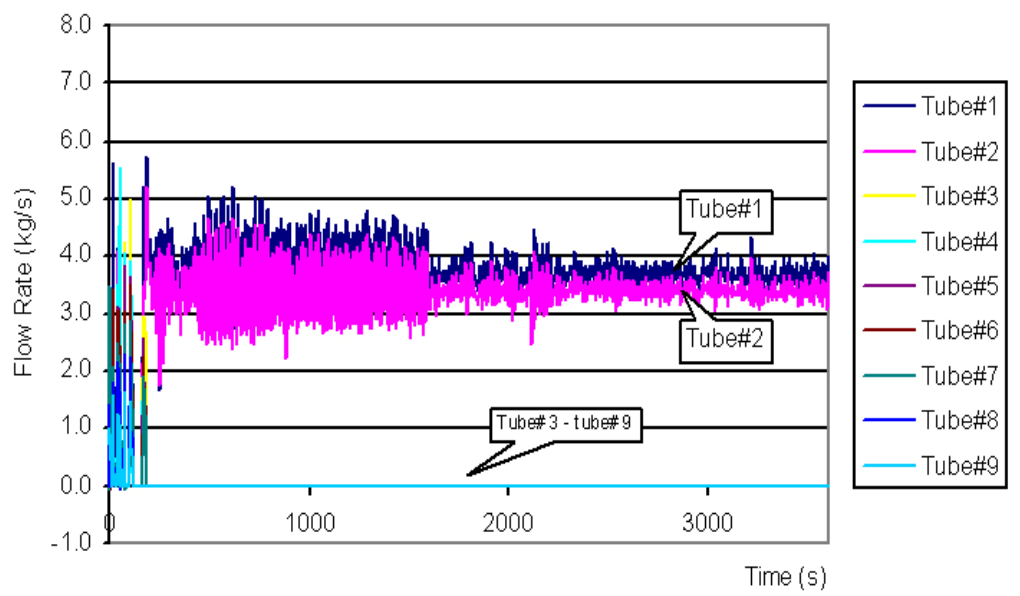

Figure 5. Tube flow rate distribution during stagnant vertical stratification.

The existence of stagnant flow in steam generator U-tubes captured by the 9-tubes model means the reduction of flow and heat transfer area. This condition more or less will affect the heat transfer to secondary side. The effect of this situation can be clearly seen if we compare heat transfer rate between single tube and 9-tubes models. Although the single tube model result was quite oscillatory, the average value somehow still can be compared. The calculation show that using the 9-tubes model and with the existence of stagnant vertical stratification in most of tubes and continuos flow in two short tubes, the heat transfer will be $15 \%$ less than using single-tube model. The two tubes with continuos flow in the model equivalent with 40 tubes in real steam generator. This result supports claim in [2] that the non uniform behavior become the reason behind over prediction of heat transfer during LOCA transient. A closer look on the heat transfer in each tube shows that $63 \%$ of heat transfer occurred in the two tubes with continuos flows and the remainder occurred in tube with stagnant flows (see Figure 6). The tube with stagnant flow still play significant contribution to the heat transfer because vapor are distributed to all stagnant tube and due to its density it will naturally go up and then will condense in tube. By the reason of vapor bring much higher enthalpy than water, small fraction of vapor releases significant heat during condensation. 


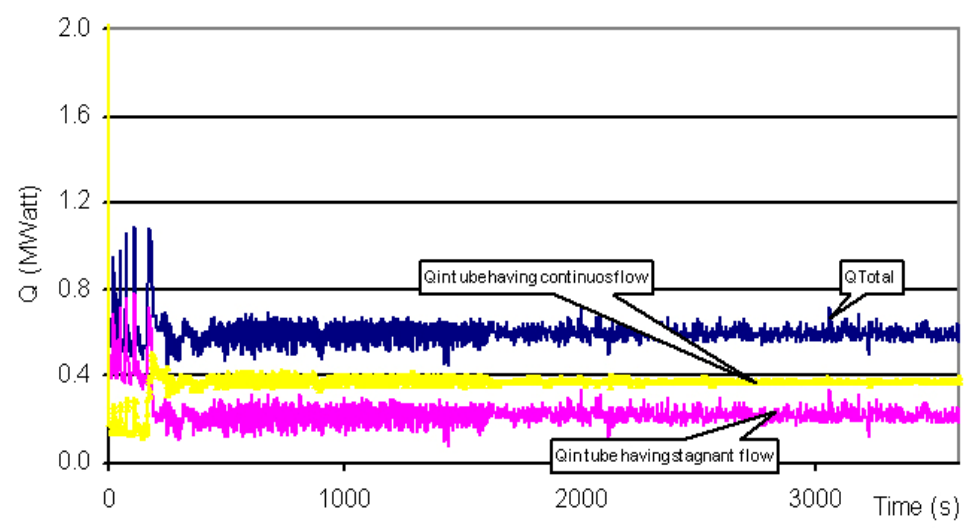

Figure 6. Heat transfer distribution based on flow mode.

Realizing that the condition of final non-uniformity among U-tubes is affected by on how the boundary condition is imposed as in the $100 \%$ of mass inventory case, it can be considered that calculation for the $75 \%$ of mass inventory boundary condition data can lead to different tubes having continuos flow. A trial simulation using different way to reach the boundary condition ended with tube\#1, tube\#5 and tube\#8 having continuos flow while other tubes having stagnant vertical stratification mode. The three tubes with continuos flow in this result is equivalent with 49 tubes in real steam generator. The average heat transfer was about $12 \%$ lower than using single tube model. This shows that less number of U-tubes having continuous flow will transfer less heat to secondary side.

Although using 9-tubes model there is significant reduction on heat transfer rate compared with the single tube model as described before, the grouping into 9 bunches still have possibility to over predict the heat transfer rate. This because single tube in the model is equivalent on average with 15 tubes in real steam generator. Realizing that the tube with continuos flow play significant influence on heat transfer, this suggests that in order to get more accurate result for transient involving flow stagnation, greater number of group is needed. However such an effort is a trade in between precision and calculation cost.

\section{CONCLUSIONS}

Steady-state natural circulation (NC) in the PWR geometry was analyzed using the RELAP5/MOD3 code focusing on non-uniform flow among steam generator (SG) U-tubes that was observed in the ROSA/LSTF experiments. Two steady-state experiments were selected for the analysis to represent high and low pressure conditions during accidents in PWR. For both experiments, the primary mass inventory was the main test parameter, while the other parameters were kept constant at a specified value. 
The SG behavior were analyzed using the partial SG model with one and nine flow paths in the primary side and using boundary conditions as in experiment. The imposed boundary conditions were flow rate, quality, pressure of the inlet side of the primary and feed water temperature, liquid level, and pressure in the secondary. In general, the simulations using the model of nine tubes were capable to capture important non uniform phenomena such as reverse flow, fill-and-dump, and stagnant vertical stratification. As a result of appropriate simulation of the non-uniform flow, the calculated SG outlet flow in the primary loop was stable as observed in the experiments.

Effects of the non-uniform flow on the heat transfer from the primary to secondary were dependent on calculated cases. For the case of high pressure and $100 \%$ mass inventory, three flow distributions among tubes were calculated from the same imposed boundary conditions. The calculated flow distributions were i) uniform, ii) mostly normal and partially reversed through the longest tube, and iii) reversed through the shortest tube. It seems the history of transient plays an important role on the selection of the flow distribution among tubes. Interestingly, the calculated heat transfer rates were almost the same among the three flow distributions.

On the other hand, the calculated heat transfer rates were $6 \%$ lower when the fill and dump mode was simulated using the 9 tubes model for the case of high pressure and $75 \%$ mass inventory. Similarly, the heat transfer rate was $15 \%$ lower when the coexistence of the flow stratification and two phase flow was simulated for the case of low pressure and $75 \%$ mass inventory. These results clearly indicate the importance of the simulation of the non-uniform flow in predicting both the flow stability and heat transfer between the primary and secondary.

Furthermore, difficulties were found in establishing the steady state condition especially for the low pressure analysis. Only when the inlet flow rate was carefully imposed, stable NC behavior was obtained.

\section{REFERENCES}

1. Y. KUKITA et al., Nuclear Science and Engineering , 99, 289 (1988).

2. YONOMOTO, T., ANODA,Y., "Thermal-hydraulic Research on Next Generation PWRS Using ROSA/LSTF", IAEA-TECDOC., 1149, 233 (2000).

3. SCHULTZ, R. R., CHAPMAN, J.C.,KUKITA. Y., et al., "Single and two phase natural circulation in Westinghouse pressurized water reactor simulators: phenomena, analysis and scaling", Proc. of the Winter Annual Meeting of ASME, Boston, MA, FED. 61, HTD. 92, 59 (1987) 
4. The ROSA-V group, "ROSA-V Large Scale Test Facility (LSTF) System description for The Third and Fourth Simulated Fuel Assemblies “, JAERI-Tech 2003-037, March (2003).

5. RELAP5 DEVELOPMENT TEAM, "RELAP5/MOD3 Code Manual", NUREG/CR-5535, INEL-95/0174, 1 (1995). 